\title{
Effect of Walking Speed Intervention for Stroke Hemiplegia Using Neurorehabilitation-Robot
}

\author{
Hirofumi Tanabe1, Toshimasa Mikawa1, Akihiko Kondo', Hiroshi Tanabe² \\ ${ }^{1}$ Department of Medical Treatment for Health, Shonan University of Medical Sciences, Yokohama, Kanagawa, Japan \\ ${ }^{2}$ Department of Occupational Therapy, Yokohama Rehabilitation Center, Yokohama, Kanagawa, Japan \\ Email: hirofumi.tanabe@sums.ac.jp
}

How to cite this paper: Tanabe, H., Mikawa, T., Kondo, A. and Tanabe, H. (2019) Effect of Walking Speed Intervention for Stroke Hemiplegia Using Neurorehabilitation-Robot. Health, 11, 1487-1492. https://doi.org/10.4236/health.2019.1111111

Received: October 10, 2019

Accepted: November 1, 2019

Published: November 4, 2019

Copyright (c) 2019 by author(s) and Scientific Research Publishing Inc. This work is licensed under the Creative Commons Attribution International License (CC BY 4.0).

http://creativecommons.org/licenses/by/4.0/

\begin{abstract}
Sufficient hip joint extension range of motion is important in improving the walking speed of patients with spastic hemiplegia. In this study, we developed a piston device for the hip (PDH) that simulates the action of the piston technique for hip joints (PTH), which is a method for improving hip joint extension range of motion. We then evaluated the efficacy of PDH on 10 spastic hemiplegia patients suffering from a limited range of hip joint extension. Results confirmed rapid improvement of hip joint range of motion and increase in walking speed.
\end{abstract}

\section{Keywords}

Device, Gait, Step Length, Hemiplegia

\section{Introduction}

Since the loss of walking ability is a major problem after stroke [1] [2], recovery of walking is a priority goal for most patients [3] [4]. Friedman showed that the sooner the individual with a history of stroke attained the ability to ambulate, the more likely it was that independent walking would be re-established [2]. Rehabilitation training is essential in increasing the walking speed of patients with spastic hemiplegia. Reasons for a loss of walking speed in hemiplegia patients include shortening of step width following a period of standing. This occurs because hip joint flexor spasticity and flexor contraction are responsible for producing range in hip joint extension, and standing prevents the hip joint from extending [5]. Most stroke patients are reduced walking speed and longer stance phases, greater on the unaffected side, are reported [6].

The first author of this report, an occupational therapist, developed a novel treatment methodology known as PTH designed to increase range of motion 
during hip joint extension. This treatment can immediately improve spastic weakening and contraction of the hip joint flexor responsible for producing loss of spastic side hip joint extension range in those with spastic hemiplegia. This piston technique was developed to improve the spastic weakening and contraction of digit flexors in spastic hands, and the efficacy of this treatment is also currently being studied. As shown in Figure 1, the hip joint piston technique involves an approximate $1 \mathrm{~cm}$ vertical vibration of the femoral head in the posterior (dorsal) direction for about 10 cycles at a frequency of 5 cycles per second $(5 \mathrm{~Hz})$. However, this manual technique would overwork a therapist and be difficult to perform on individuals with large bodies. For this reason, PDH was developed to simulate this technique. In this study, $\mathrm{PDH}$ was performed on spastic

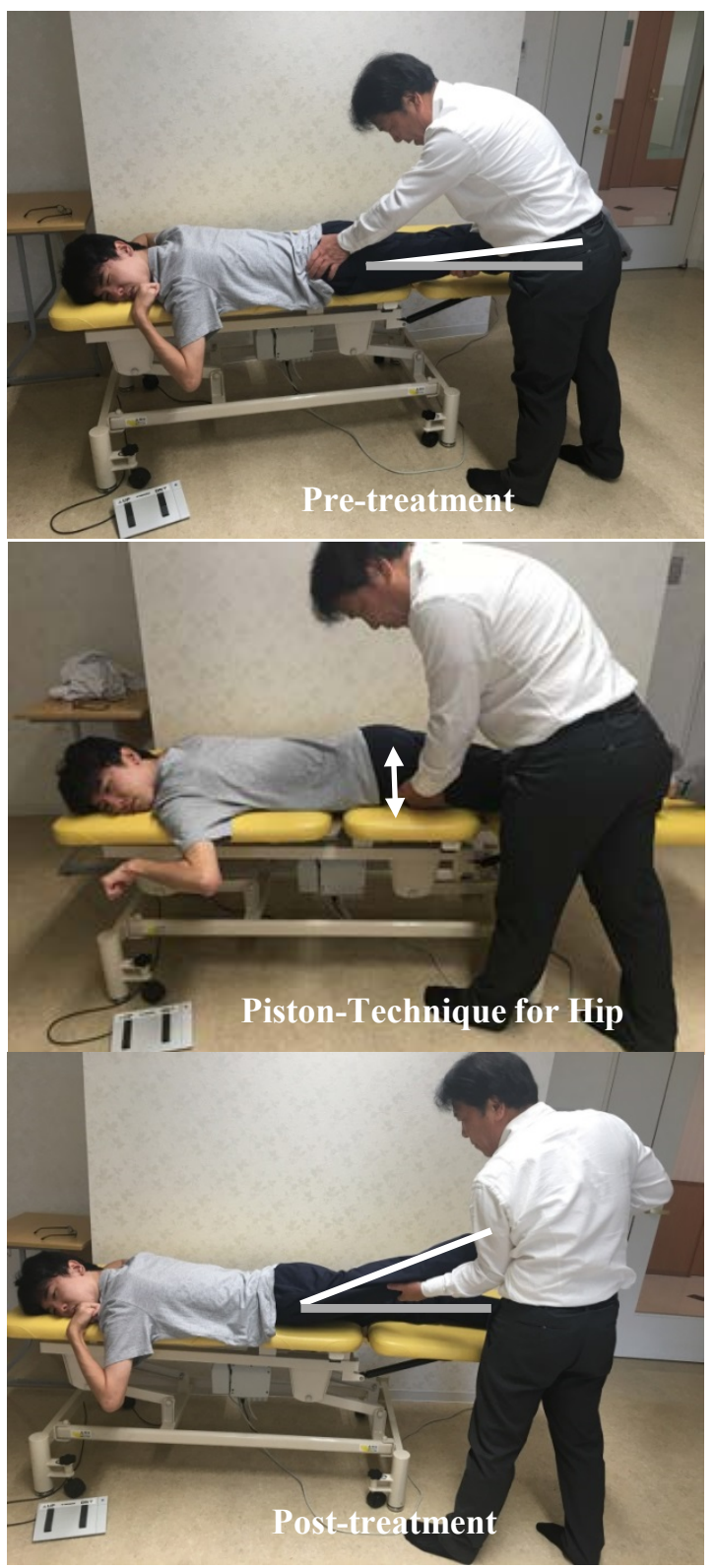

Figure 1. State of treatment of PTH. 
hemiplegia patients suffering from limited hip joint extension range of motion. Moreover, we investigated the positive effects on hip extension range of motion and walking speed.

\section{Validity Verification}

In order to verify the effectiveness of the developed PDH, a clinical study was conducted on ten persons with spastic hemiplegia and extension limited in the hip joint. Subjects were recruited via the internet. The conditions for participating were as follows: that six months had passed since the occurrence of a stroke, that there was a limited range of extension for the hip joints, that there was no aching in the extremities, and that the subject is able to assume a prone position. Of the 14 subjects who were recruited, two who were unable to assume a prone position and two who had aching in the knees were excluded, leaving 10 subjects. The subjects participated in a one-day clinical study from May to June 2019 at the clinic where the first author worked. For the therapy, the subjects were first asked to assume a prone position on an examination bed, and they were made to lay in such a way that their hip joints slightly protruded from the edge. The therapist then moved the upper part of the PDH to a position $5 \mathrm{~cm}$ in the distal direction from the hip joint. The therapist held down the patient's paralyzed foot on the brace of the $\mathrm{PDH}$ and gradually increased the speed of a reciprocating motion from a stopped state while confirming the effects of the treatment. PDH treatment is shown in Figure 2. The therapist set the rotational speed to 304 [rpm] which corresponds to a frequency of $5 \mathrm{~Hz}$ and the length of the crank arm to $0.020[\mathrm{~m}]$ which corresponds to a stroke of $0.040[\mathrm{~m}]$. The treatment time was approximately 30 seconds depending on the patient's condition of spastic paralysis. The speed during PDH treatment was five cycles per second. The therapist stopped the PDH when judging that it had an effect. The effects of $\mathrm{PDH}$ treatment were assessed using passive range of motion (Passive-ROM) test [7] and the 10 Meter Walk Test [8] [9].

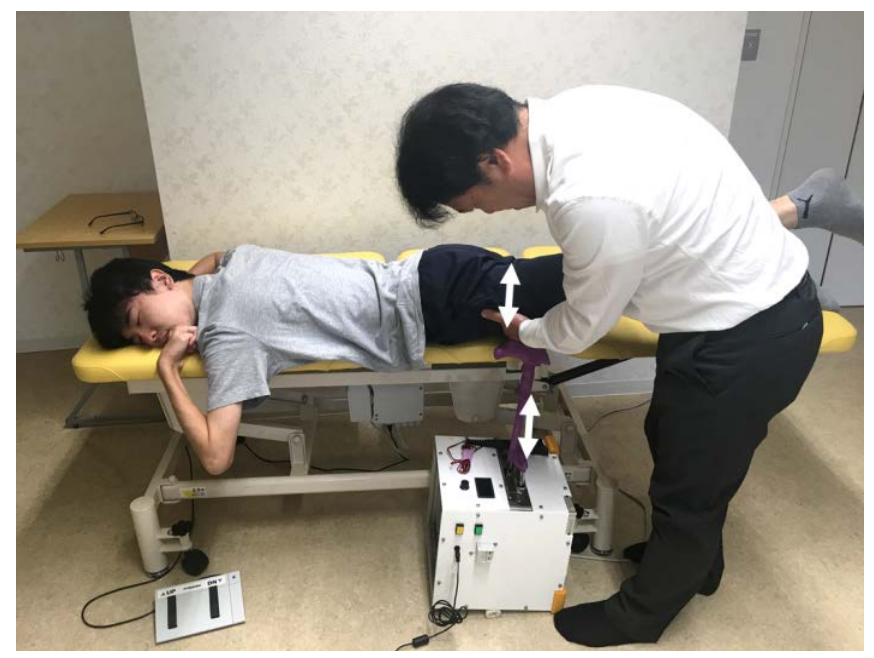

Figure 2. Prototype of the PDH. 


\section{Results}

The study was completed by 10 participants. The results are summarized in $\mathrm{Ta}$ ble 1. Passive-ROM increased range of motion in all participants. Pre-treatment hip joint extension had a mean of -8.6 degrees (standard deviation of 4.6), but post-treatment extension improved to a mean of 25.7 degrees (standard deviation of 6.5). The 10 Meter Walk Test also showed improvement in all participants. Pre-treatment mean duration was 14.1seconds (standard deviation of 1.4), but post-treatment duration improved to a mean of 9.5 seconds (standard deviation of 1.3) (see chart and Figure 3). Both results also had significant differences between pre-treatment and post-treatment (Wilcoxon signed-rank test $\mathrm{p}<0.01$ ).

Table 1. Summary of results.

\begin{tabular}{|c|c|c|c|c|}
\hline \multirow{3}{*}{ No } & \multirow{2}{*}{\multicolumn{2}{|c|}{ Hip extension range of motion }} & \multirow{2}{*}{\multicolumn{2}{|c|}{$\frac{10 \text { Meter Walk Test }}{(\text { second })}$}} \\
\hline & & & & \\
\hline & pre & post & pre & post \\
\hline 1 & -10 & 20 & 12.6 & 8.8 \\
\hline 2 & -20 & 25 & 13.8 & 8.5 \\
\hline 3 & -5 & 25 & 13.5 & 8.7 \\
\hline 4 & -5 & 30 & 13.7 & 9 \\
\hline 5 & -10 & 25 & 11.9 & 7.1 \\
\hline 6 & -5 & 35 & 12.7 & 8.2 \\
\hline 3 & -5 & 35 & 14.1 & 10 \\
\hline 4 & -10 & 20 & 15.5 & 11.1 \\
\hline 5 & -10 & 20 & 14.8 & 9.2 \\
\hline 6 & -5 & 30 & 14.2 & 11.5 \\
\hline 7 & -10 & 25 & 13.4 & 9.5 \\
\hline 8 & -5 & 35 & 14.5 & 9.5 \\
\hline 9 & -15 & 15 & 17.6 & 10.9 \\
\hline 10 & -5 & 20 & 15.2 & 11.6 \\
\hline
\end{tabular}
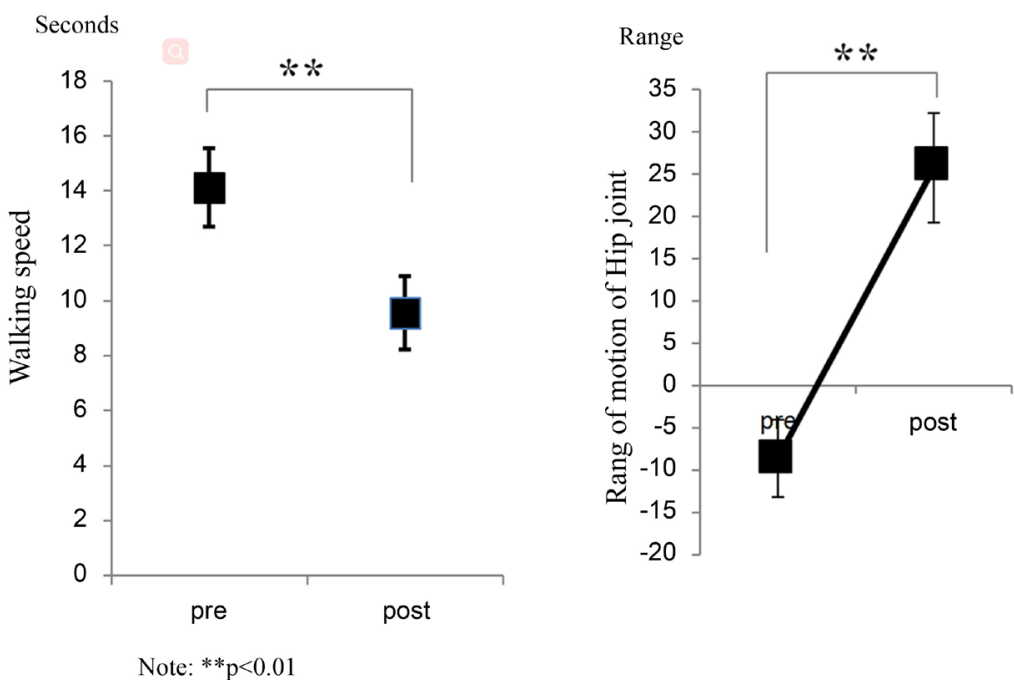

Figure 3. Changes in extension range of motion of Hip joint and walking speed. 


\section{Discussion}

Strengthening the lower limbs has been reported to be effective as a method of speeding up hemiplegic gait due to stroke, and it was reported long ago that strengthening the extensor muscles of the lower limbs was effective [10]-[14]. However, in recent years, it has been reported that the Trailing Limb Angle (TLA), which represents the extension angle of the hip joints during the late stance phase, increases the driving force of the stance phase and improves walking speed [15] [16]. While it has been reported that encouraging the subject to bring the foot on their paralyzed side as far forward as possible is one effective approach to increasing the TLA and promoting an improvement in walking speed75, because this method assumes that there is no limited range of extension for the hip joints, it is necessary to prioritize improving the range of extension of the hip joints before performing this method. In this research, after providing therapy via PDH on subjects with a limited range of extension for the hip joints due to stroke hemiplegia, the range of extension for the hip joints improved after just five minutes or less. In addition, after receiving this therapy, the subjects' walking speed improved greatly. This is likely due to the increase in the range of motion for the hip joints causing an increase in the TLA, which resulted in an increase in walking speed. With regards to the mechanism that allows this piston exercise to improve the shortening of the hip joint flexors, rapidly moving the femur head back and forth causes the iliac muscle and psoas major muscle to repeatedly extend and relax in short bursts very rapidly. Because this becomes difficult to relay to the central nerves that control muscle strain as a deep sensation from the proprioceptors in the lower limbs (it is no longer clear what position the lower limbs are in), one can postulate that the muscle strain likely resets, but this is just a hypothesis and requires further verification.

\section{Summary}

In this study, we developed a piston device for the hip (PDH) that simulates the action of the piston technique for hip joints (PTH), which is a method for improving hip joint flexion range of motion. We then evaluated the efficacy of $\mathrm{PDH}$ on 10 spastic hemiplegia patients suffering from a limited range of hip joint flexion. Results confirmed rapid improvement of hip joint range of motion and increase in walking speed. Hip joint extension range of motion treatment for static hemiplegia patients using PDH is expected to reduce the burden placed on therapists as well as shorten the time required to improve walking function in hemiplegic individuals.

\section{Conflicts of Interest}

The authors declare no conflicts of interest regarding the publication of this paper.

\section{References}

[1] Wade, D.T. and Hewer, R.L. (1987) Functional Abilities after Stroke: Measurement, 
Natural History and Prognosis. Journal of Neurology, Neurosurgery, and Psychiatry, 50, 177-182. https://doi.org/10.1136/jnnp.50.2.177

[2] Friedman, P.J. (1990) Gait Recovery after Hemiplegic Stroke. International Disability Studies, 12, 119-122. https://doi.org/10.3109/03790799009166265

[3] Mumma, C.M. (1986) Perceived Losses Following Stroke. Rehabilitation Nursing, 11, 19-22. https://doi.org/10.1002/j.2048-7940.1986.tb00502.x

[4] Bohannon, R.W., Horton, M.G. and Wikholm, J.B. (1991) Importance of Four Variables of Walking to Patients with Stroke. International Journal of Rehabilitation Research, 14, 246-250. https://doi.org/10.1097/00004356-199109000-00010

[5] Yamamoto, S. (2002) Gait Analysis of Patients with Cerebrovascular Disease. Rigakuryoho Kagaku, 17, 3-10.

[6] Lay, A.N., Hass, C.J., Richard Nichols, T. and Gregor, R.J. (2007) The Effects of Sloped Surfaces on Locomotion: An Electromyographic Analysis. Journal of Biomechanics, 40, 1276-1285. https://doi.org/10.1016/j.jbiomech.2006.05.023

[7] Gajdosik, R.L. and Bohannon, R.W. (1987) Clinical Measurement of Range of Motion: Review of Goniometry Emphasizing Reliability and Validity. Physical Therapy, 67, 1867-1872. https://doi.org/10.1093/ptj/67.12.1867

[8] Tyson, S. and Connell, L. (2009) The Psychometric Properties and Clinical Utility of Measures of Walking and Mobility in Neurological Conditions: A Systematic Review. Clinical Rehabilitation, 23, 1018-1033. https://doi.org/10.1177/0269215509339004

[9] Bohannon, R.W. (1997) Comfortable and Maximum Walking Speed of Adults Aged 20-79 Years: Reference Values and Determinants. Age Ageing, 26, 15-19. https://doi.org/10.1093/ageing/26.1.15

[10] Nakamura, R., Watanabe, S., Handa, T. and Morohashi, I. (1988) The Relationship between Walking Speed and Muscle Strength for Knee Extension in Hemiparetic Stroke Patients: A Follow-Up Study. The Tohoku Journal of Experimental Medicine, 154, 111-113.

[11] Bohannon, R.W. (1989) Selected Determinants of Ambulatory Capacity in Patients with Hemiplegia. Clinical Rehabilitation, 3, 47-53. https://doi.org/10.1177/026921558900300107

[12] Bohannon, R.W. (1990) Correlation of Knee Extensor Muscle Torque and Spasticity with Gait Speed in Patients with Stroke. Archives of Physical Medicine and Rehabilitation, 71, 330-333.

[13] Bohannon, R.W. (1992) Knee Extension Power, Velocity and Torque: Relative Deficits and Relation to Walking Performance in Stroke Patients. Clinical Rehabilitation, 6, 125-131. https://doi.org/10.1177/026921559200600206

[14] Nadeau, S., Gravel, D., Arsenault, A.B. and Bourbonna, D. (1999) Plantarflexor Weakness as a Limiting Factor of Gait Speed in Stroke Subjects and the Compensating Role of Hip Flexors. Clinical Biomechanics, 14, 125-135. https://doi.org/10.1016/S0268-0033(98)00062-X

[15] Hsiao, H. and Knar, B.A. (2015) The Relative Contribution of Ankle Moment and Trailing Limb Angle to Propulsive Force during Gait. Human Movement Science, 39, 212-221. https://doi.org/10.1016/j.humov.2014.11.008

[16] Hsiao, H. and Knar, B.A. (2015) Mechanisms to Increase Propulsive Force for Individuals Poststroke. Journal of NeuroEngineering and Rehabilitation, 12, Article No. 40. https://doi.org/10.1186/s12984-015-0030-8 